\title{
Proteinuria in Passive Heymann Nephritis Is Associated with Lipid Peroxidation and Formation of Adducts on Type IV Collagen
}

\author{
T. James Neale, * Prakesh P. Ojha, Markus Exner, Helga Poczewski, Beate Rüger, ${ }^{\star}$ Joseph L. Witztum, ${ }^{\ddagger}$ Paul Davis, ${ }^{\star}$ and \\ Dontscho Kerjaschki \\ Division of Ultrastructural Pathology and Cell Biology, Institute of Clinical Pathology, University of Vienna, A 1090 Vienna, Austria; \\ ${ }^{*}$ Department of Medicine, Wellington School of Medicine, Wellington, New Zealand 7334; and ${ }^{\ddagger}$ Division of Endocrinology and \\ Metabolism, Department of Medicine, University of California San Diego, La Jolla, California 92093
}

\section{Abstract}

Passive Heymann nephritis (PHN) is a model of human membranous nephropathy that is characterized by formation of granular subepithelial immune deposits in the glomerular capillary wall which results in complement activation. This is causally related to damage of the filtration barrier and subsequent proteinuria. The local accumulation of injurious reactive oxygen species (ROS) is a major effector mechanism in PHN. ROS may induce tissue damage by initiating lipid peroxidation (LPO). In turn, this leads to adduct formation between breakdown products of LPO with structural proteins, such as formation of malondialdehyde (MDA) or 4-hydroxynonenal-lysine adducts. To examine the role of LPO in the development of proteinuria we have localized MDA and 4-hydroxynoneal-lysine adducts in glomeruli of PHN rats by immunofluoresence microscopy, using specific monoclonal antibodies. By immunogold electron microscopy, MDA adducts were localized to cytoplasmic vesicles and cell membranes of glomerular epithelial cells, to the glomerular basement membrane (GBM), and also to immune deposits. Type IV collagen was specifically identified as being modified by MDA adducts, using a variety of techniques. Collagenase pretreatment of GBM extracts indicated that the NC-1 domain of type IV collagen was a site of adduct formation. When LPO was inhibited by pretreatment of PHN rats with the antioxidant probucol, proteinuria was reduced by $\sim \mathbf{8 5 \%}$, and glomerular immunostaining for dialdehyde adducts was markedly reduced, even though the formation of immune deposits was not affected. By contrast, lowering of the serum cholesterol levels had no influence on the development of proteinuria.

These findings are consistent with the premise that ROSinduced glomerular injury in PHN involves LPO and that this results not only in damage of cell membranes but in modification of type IV collagen in the GBM as well. The close temporal correlation of the occurrence of LPO with

Dr. Neale was on sabbatical leave from the Department of Medicine, Wellington School of Medicine, Wellington, New Zealand.

Address correspondence to Dontscho Kerjaschki, M.D., Department of Clinical Pathology, Division of Ultrastructural Pathology and Cell Biology, Währinger Gürtel 18-20, A 1090 Vienna, Austria.

Received for publication 4 January 1994 and in revised form 26 April 1994.

\section{J. Clin. Invest.}

(C) The American Society for Clinical Investigation, Inc.

0021-9738/94/10/1577/08 $\$ 2.00$

Volume 94, October 1994, 1577-1584 proteinuria and the ability of probucol to inhibit proteinuria support a causal role for LPO in the the alteration of the glomerular permselectivity which results in proteinuria. ( $J$. Clin. Invest. 1994. 94:1577-1584.) Key words: glomerular damage $\bullet$ proteinuria $\cdot$ reactive oxygen species $\cdot$ lipid peroxidation - matrix proteins

\section{Introduction}

Membranous nephropathy is an immune disease of the human kidney glomerulus that frequently leads to glomerular scarring and chronic renal insufficiency, necessitating renal replacement therapy by chronic dialysis or kidney transplantation (1). Passive Heymann nephritis (PHN) ${ }^{1}$ is a classical experimental model of membranous nephropathy which is induced in rats by injection with heterologous antibody against a crude autologous tubular antigen, FxlA (for reviews see references 2 and 3 ). The hallmarks of both the human and the rat diseases are the development of subepithelial immune deposits in the glomerular capillary walls and heavy proteinuria which commences in PHN 5-7 d after injection of nephritogenic antibody (1-3).

The basic molecular mechanisms by which the typical subepithelial immune deposits are formed in PHN have become apparent (3-6), but the pathogenesis of proteinuria is unknown, although several steps of functional importance have been explored recently. For example, treatment of rats with oxygen radical scavengers efficiently reduced proteinuria while the formation of immune deposits was not affected (7). In PHN the glomerular epithelial cells express cytochrome $b_{558}(8)$, an integral component of the NADPH-oxidoreductase enzyme complex that is essential for the respiratory burst in activated neutrophilic granulocytes (9). This enzyme complex generates reactive oxygen species (ROS) locally which are distributed within the glomerular basement membrane (GBM) of proteinuric rats with PHN (8). ROS cause tissue injury directly, such as by cleavage of peptide bonds (10), or indirectly by initiating myeloperoxidase- $\mathrm{H}_{2} \mathrm{O}_{2}$-halide reactions (11), or by lipid peroxidation (LPO) which results, among other consequences, in the generation of highly reactive aldehydes which can then complex with lysine residues of proteins $(10-13)$. Since there is evidence for the involvement of ROS in experimental renal diseases $(7,8,11,14,15)$, we have examined the contribution of LPO to the development of proteinuria in PHN.

1. Abbreviations used in this paper: BHT, butylated hydroxytoluene; 4-HNE, 4-hydroxynonenal; LPO, lipid peroxidation; MDA, malondialdehyde; PHN, passive Heymann nephritis; ROS, reactive oxygen species; TBS, Tris-buffered saline. 


\section{Methods}

Induction of PHN and reduction of proteinuria by probucol. PHN was induced in 220-250-g male Sprague-Dawley rats by intravenous injection of $0.5 \mathrm{ml}$ of sheep anti-Fx1A serum as described (8). Normal rats and those injected $7 \mathrm{~d}$ previously were studied. Proteinuria was determined by Bradford assay (16). Probucol (Merrell Dow Pharmaceuticals Inc., Cincinnati, $\mathrm{OH}$ ), a synthetic antioxidant structurally closely related to butylated hydroxytoluene (BHT) and known to inhibit LPO (17-19), was administered to rats for $21 \mathrm{~d}$ before the induction of PHN by mixing with standard rat chow at $1 \%$ by weight. Rats were found to consume $\sim 25 \mathrm{~g}$ of powdered pelleted food each per day in lead-in experiments conducted to ensure acceptance of this form of feeding. Additional rats $(n=11)$ were fed with the HMG CoA reductase inhibitor simvastatin ( $1 \mathrm{mg} / \mathrm{d}$ ) (Merck Sharp \& Dohme, St. Louis, MO), for $21 \mathrm{~d}$, to reduce serum cholesterol to match the cholesterol lowering produced by probucol. $7 \mathrm{~d}$ after induction of PHN, the rats were housed in metabolic cages to collect urine for the quantitation of 24 -h proteinuria and were then killed. The kidneys were perfused in situ with $4 \%$ paraformaldehyde/7\% sucrose/50 $\mu \mathrm{M}$ BHT for immunohistochemistry (8).

The use of rats in these experiments was approved by the Commission for Animal Research at the University of Vienna, by the Austrian Ministry of Science, and by the Animal Ethical Committee of the Wellington School of Medicine.

Antibodies. The mouse monoclonal antibody MDA-2 was raised against murine malondialdehyde (MDA)-LDL and was specific for MDA-lysine adducts (20). A polyclonal guinea pig anti-MDA antiserum with similar specificity was raised against autologous MDA-LDL $(20,21)$. The mouse monoclonal antibody NA5 with specificity for $4-$ hydroxynonenal (4-HNE) was raised using murine 4-HNE modified LDL (20-22). F( $\left(\mathrm{ab}^{\prime}\right)_{2}$ goat anti-guinea pig Ig/FITC (Dako Corp., Carpinteria, CA) was absorbed with rat serum and shown to have reactivity only with guinea pig immunoglobulins.

Immunofluorescence microscopy. 1- $\mu \mathrm{m}$-thick frozen sections were cut on a Reichert Ultracut ultramicrotome (Leica-Reichert, Vienna, Austria), using an F4 cryo attachment, from kidneys of normal control rats, 7-d PHN rats, and 7-d PHN rats pretreated with either probucol or simvastatin. The kidneys were fixed by perfusion with freshly prepared $4 \%$ paraformaldehyde $/ 7 \%$ sucrose $/ 50 \mu \mathrm{M}$ BHT as described (8). Sheep IgG was detected by direct immunofluorescence microscopy using $\mathrm{F}\left(\mathrm{ab}^{\prime}\right)_{2}$ rabbit anti-sheep IgG (Jaxell Accurate, Westbury, NY). Some sections were incubated successively with $1 \%$ deoxycholate for $15 \mathrm{~min}$ and $1 \%$ Triton X-100 for 30 min to provide basement membrane preparations free of cells, followed by washing in Tris-buffered saline (TBS) and quenching by 1:10 diluted normal goat serum in TBS. The sections were treated with a four-layer sandwich for amplification of the signal (8). Briefly, sections were incubated with anti-MDA or anti-4-HNE

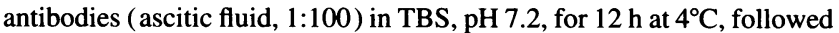
by FITC-sheep anti-mouse IgG (Dako Corp.) preabsorbed with normal rat serum for $45 \mathrm{~min}$, followed by mouse monoclonal anti-FITC 1:20 (Sigma Immunochemicals, St. Louis, MO) for $45 \mathrm{~min}$ and a second application of FITC-sheep anti-mouse antibody. Immunohistochemical control sections of 7-d PHN glomeruli did not stain with the individual enhancing sandwich components. Negative controls were performed by omission of the primary antibody. Sections were mounted in $1 \% p$ phenylene-diamine-glycerol, $\mathrm{pH} 8.0$, and examined with a Leitz fluorescence microscope.

Immunogold electronmicroscopy. Immunogold electronmicroscopy was performed as described $(8,23,24)$. Ultrathin frozen sections of perfusion-fixed kidneys (4\% paraformaldehyde/7\% sucrose/50 $\mu \mathrm{M}$ BHT) from normal control and 7-d PHN rats were incubated with monoclonal anti-MDA antibody in PBS, containing $1 \%$ ovalbumin, followed by a bridging affinity-purified rabbit $\mathrm{F}\left(\mathrm{ab}^{\prime}\right)_{2}$ anti-mouse IgG (preabsorbed with rat and goat IgG) and gold-labeled goat anti-rabbit IgG (1:10; Auroprobe; Amersham Corp., Arlington Heights, IL). In positive control experiments, sections were treated with monoclonal anti-C5b-9 IgG (a gift from Dr. W. G. Couser, Department of Internal Medicine, University of Washington, Seattle, WA). For negative con- trols, the primary antibody was omitted or replaced by an irrelevant monoclonal IgG of the same isotype.

Immunoblotting. Glomeruli were isolated by graded sieving, and lysates were prepared in reducing SDS sample buffer as described (8, 25 ). After electrophoresis in 5-15\% SDS gels ( $50 \mu \mathrm{M}$ BHT was added to the electrophoresis buffer), resolved proteins were transferred onto nitrocellulose. Strips were blocked with a buffer containing $5 \%$ dried milk, $0.01 \%$ Tween 20 , and $50 \mu \mathrm{M}$ BHT in PBS, followed by incubation with the primary antibody at room temperature for $4 \mathrm{~h}$ or overnight at $4^{\circ} \mathrm{C}$ in the blocking buffer. The MDA-2 antibody was used at a dilution of 1:1,000, anti-HNE at 1:200, and the guinea pig antiserum at 1:1,000. Some nitrocellulose transfers were also incubated in affinity-purified rabbit antibodies to rat type IV collagen, laminin (gifts of Dr. R. Timpl, Max Planck Institute for Biochemistry, Martinsried, Germany), and fibronectin (Heyl Company, Berlin, Germany), using $\sim 5 \mu \mathrm{g}$ antibody/ $\mathrm{ml}$. Development followed a 1-h incubation with the appropriate alkaline phosphatase-labeled secondary antibody (Promega Corp., Madison, WI) at a dilution of 1:10,000, using NBT and BCIP as substrates (Kirkegaard and Perry Laboratories, Inc., Gaithersburg, MD).

Radiolabeling of MDA-Schiff bases in GBMs and immunoprecipitation. Glomeruli from six kidneys of normal controls and 7-d PHN rats were isolated by graded sieving, using TBS with $1 \%$ BSA and protease inhibitors ( $10 \mu \mathrm{g} / \mathrm{ml}$ of pepstatin, antipain, and leupeptin, and $10 \mathrm{mM}$ diisopropyl fluorophosphate and benzamidine), as described $(8,25)$, and $50 \mu \mathrm{M}$ BHT. GBMs were prepared by extraction with $2 \%$ deoxycholate in $20 \mathrm{mM}$ Hepes buffer, pH 7.4, sonication, vortex mixing, centrifugation at $2,000 \mathrm{~g}$ for $5 \mathrm{~min}$, and washing in TBS. ${ }^{3} \mathrm{H}$-labeling of Schiff bases (26), electrophoresis, and autoradiography of labeled proteins were performed as follows: briefly, ${ }^{3} \mathrm{H}$-sodium cyanoborohydride ( $\mathrm{Am}$ ersham International, Buckinghamshire, UK) was added to the suspended isolated GBMs ( $2.5 \mathrm{mCi}$ per GBM preparation) in TBS, pH 7.2 , and shaken overnight at $20^{\circ} \mathrm{C}$. After washing, $200 \mu \mathrm{l}$ of reducing SDS sample buffer (3.6\% SDS, $2 \% \beta$-mercaptoethanol, $20 \mathrm{mM}$ Tris phosphate buffer, $\mathrm{pH} 6.8,10 \mathrm{mM}$ EDTA) was added, heated to $100^{\circ} \mathrm{C}$, and aliquots were applied to 5-12\% gradient polyacrylamide SDS gels. After electrophoresis, the gels were fixed in propanol/water/acetic acid (25:65:10) for $30 \mathrm{~min}$ and then placed into Amplify fluorographic reagent (Amersham International) for $30 \mathrm{~min}$ before drying. The gels were then applied to X-Omat AR film (Eastman Kodak Co., Rochester, NY) in film cassettes with amplification screens and exposed for $1 \mathrm{~h}$ to $7 \mathrm{~d}$ at $-80^{\circ} \mathrm{C}$

For immunoprecipitation the radiolabeled GBMs were extracted for 45 min with $500 \mu \mathrm{l} 1 \%$ SDS, $1 \% \beta$-mercaptoethanol, $10 \mathrm{mM}$ EDTA in $20 \mathrm{mM}$ Tris $/ \mathrm{HCl}, \mathrm{pH} 7.4$, at $20^{\circ} \mathrm{C}$, sonicated, and boiled, and the supernatants were lyophilized. The dried proteins were dissolved in a radioimmunoprecipitation buffer $(4$, final detergent concentrations were $0.1 \%$ SDS, $1 \%$ Triton X-100, and $1 \%$ deoxycholate) and incubated with rabbit antibodies specific for laminin and type IV collagen and against rat glomerular heparan sulphate proteoglycan (gift of Dr. J. Stow, Department of Pathology, Massachusetts General Hosptial, Boston, MA) using $\sim 5 \mu \mathrm{g}$ antibody $/ 200 \mu \mathrm{l}$ labeled GBMs at $4^{\circ} \mathrm{C}$ overnight. Immune complexes were collected with protein A-Sepharose (Pharmacia LKB Biotechnology Inc., Piscataway, NJ) and were electrophoresed on 3.6$8 \%$ gradient SDS gels. Autoradiography was performed as described above.

Detection of MDA in the NC-1 domain of type IV collagen. Glomeruli isolated from 7-d PHN and control rats were suspended in $20 \mathrm{mM}$ Hepes, $\mathrm{pH} 7.4$, containing $2 \%$ deoxycholate. Thereafter the preparation proceeded in the following steps: $(a)$ the mixture was subjected to three cycles of sonication ( $5 \mathrm{~min}$ at $20 \mathrm{kc} / \mathrm{s}$ ), followed by vigorous vortex mixing. After centrifugation at $11,000 \mathrm{~g}$ for $5 \mathrm{~min}$, the supernatant was removed, and the pellet was resuspended in Hepes/deoxycholate buffer and centrifuged. $(b)$ Supernatants were combined, sodium cyanoborohydride $(2.8 \mathrm{mg} / \mathrm{mg}$ wet wt of glomeruli) was added, and reduction was performed overnight at $4^{\circ} \mathrm{C}$. The reaction was stopped by the addition of glacial acetic acid $(30 \mu \mathrm{l} / \mathrm{ml})$, dialyzed against 2 liters of $50 \mathrm{mM}$ acetic acid, and lyophylized. $(c)$ The reduced extract was resuspended in $1 \mathrm{ml}$ of $1 \%$ SDS, $1 \% \beta$-mercaptoethanol, $10 \mathrm{mM}$ EDTA, $20 \mathrm{mM}$ 

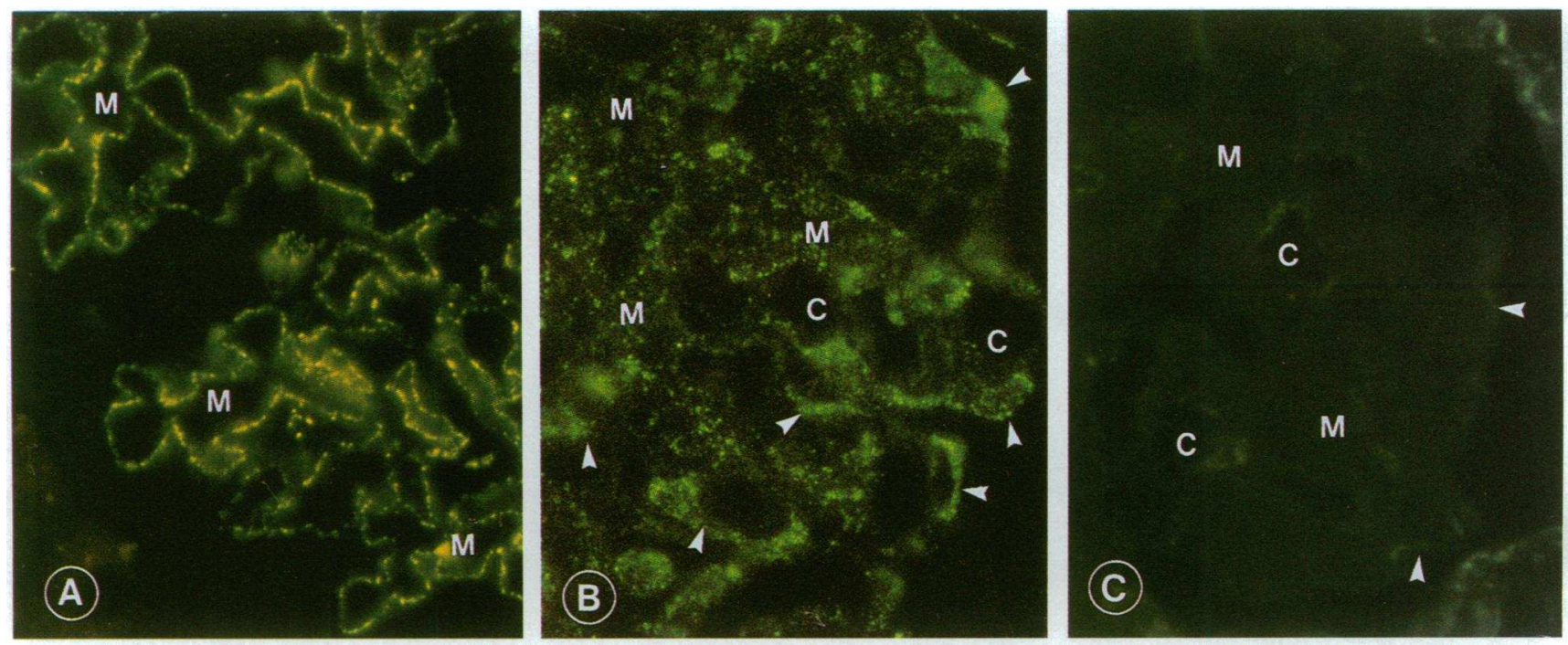

Figure 1. Localization of $(A)$ sheep anti-rat Fx1A in immune deposits, $(B)$ MDA adducts in glomeruli from proteinuric rats with 7-d PHN, and $(C)$ MDA adducts in glomeruli from 7-d PHN rats pretreated with probucol. Immunofluoresence microscopy on 1- $\mu \mathrm{m}$ frozen sections. $A$, granular deposits of IgG are shown around the peripheral glomerular capillary loops in the typical pattern of PHN. $B$, MDA adducts are shown prominently in glomerular epithelial cells in a finely granular pattern extending around the glomerular capillary loops, within the GBM, and throughout the mesangium $(M) . C$, in a probucol-pretreated rat there is a marked reduction in glomerular staining for MDA adducts, when compared with unmanipulated PHN rats in $B . \times 700$.

Tris $/ \mathrm{HCl}, \mathrm{pH} 7.4$, and sonicated three times for 2 min each. After centrifugation at $11,000 \mathrm{~g}$ for $5 \mathrm{~min}$ at $4^{\circ} \mathrm{C}$, the supernatant was removed and lyophilized and redissolved in $500 \mu \mathrm{l} 0.1 \%$ SDS and $1 \%$ deoxycholate. Type IV collagen was immunoprecipitated with anti-type IV collagen antibody (Heyl Company) at a final dilution of 1:200 by shaking at $4^{\circ} \mathrm{C}$ for $20 \mathrm{~h} .(d)$ The precipitate was recovered by centrifuging at $11,000 \mathrm{~g}$ for $10 \mathrm{~min}$ and redissolved in $0.5 \mathrm{M}$ acetic acid. This solution was divided into two portions before freeze drying. One aliquot was dissolved in $50 \mathrm{mM}$ Tris/ $\mathrm{HCl}, \mathrm{pH} 7.5,2 \mathrm{mM} \mathrm{CaCl}, 200 \mathrm{mM} \mathrm{NaCl}$. Clostridial collagenase (Millipore Corp., Bedford, MA) $(448 \mathrm{U} / \mathrm{mg})$ at $5 \mathrm{mg} / \mathrm{ml}$ was added, at a ratio of $1: 100$ by volume, and digestion proceeded at room temperature for $6 \mathrm{~h}$ before termination by the addition of EDTA. (e) Polyclonal anti-NC-1 IgG (Heyl Company) was added at a final dilution $1: 30$, and the mixture was shaken for $12 \mathrm{~h}$ at $4^{\circ} \mathrm{C}$. The immunoprecipitate was pelleted by centrifugation at $11,000 \mathrm{~g}$ for $5 \mathrm{~min}$ and dissolved in $62.5 \mathrm{mM}$ Tris $/ \mathrm{HCl}, \mathrm{pH} 6.8,20 \%$ glycerol, $2 \%$ SDS, and $0.0025 \%$ bromophenol blue before electrophoresis on a $4-$ 15\% gradient SDS-gel. $(f)$ Proteins were transferred onto Immobilon (Millipore Corp.), using a semidry transfer apparatus (Bio-Rad Laboratories, Richmond, CA). The membrane was blocked overnight in PBS, $0.1 \%$ Tween $20,2 \% \mathrm{BSA}$ at $4^{\circ} \mathrm{C}$, washed five times, and then incubated with monoclonal anti-MDA IgG $(\sim 15 \mu \mathrm{g} / \mathrm{ml})$ in the same buffer, followed by five washes. The membranes were incubated for $2 \mathrm{~h}$ at $20^{\circ} \mathrm{C}$ with anti-mouse immunoglobulin conjugated with biotin (Amersham Corp., diluted 1:1,000). After washing overnight, membranes were incubated with streptavidin-biotin-horseradish peroxidase conjugate (Amersham Corp., 1:1,000) and detected by enhanced chemiluminesence (Amersham Corp.).

Measurement of cholesterol concentrations in rat serum. Normal rats and those developing PHN with and without pretreatment with probucol or simvastatin had serum cholesterol concentrations measured by a cholesterol oxidase method (27) before induction of PHN and at $7 \mathrm{~d}$ after anti-Fx $1 \mathrm{~A}$ antibody injection.

Statistical methods. Nonparametric Wilcoxon signed rank methods were applied to determine the significance of quantitated proteinuria and cholesterol levels.

\section{Results}

Localization of adducts in glomeruli. Granular immune deposits of sheep IgG in the peripheral capillary loops typical of PHN were detected $7 \mathrm{~d}$ after intravenous injection of anti-Fx 1 A antibody (Fig. $1 \mathrm{~A}$ ). Similar immune deposits were observed in PHN rats that were pretreated with probucol or simvastatin (not shown). The kidneys taken from proteinuric PHN rats demonstrated a diffuse granular deposition of MDA-modified proteins in the glomerular epithelial cells and in the peripheral capillary loops when stained with monoclonal antibody MDA2 (Fig. $1 B$ ). Granular staining was also observed in the mesangium and in the cytoplasm and the brush border region of proximal tubules (Fig. $1 \mathrm{~B}$ ). Glomerular labeling was almost completely absent in normal controls and was markedly reduced in rats developing PHN after pretreatment with probucol (Fig. 1 $C$ ). Staining for MDA adducts was not affected by simvastatin pretreatment (not shown). The polyclonal guinea pig anti-MDA antibody, as well as the monoclonal antibody to 4-HNE, stained glomeruli of rats with 7-d PHN in a similar pattern, but with reduced intensity when compared with that of the monoclonal antibody MDA-2 (not shown).

MDA adducts were localized within vesicles and the cytoplasm of glomerular epithelial cells by immunogold labeling on ultrathin frozen sections of formaldehyde-fixed kidneys (Fig. 2 ). Gold particles were also detected along the cell membranes of the glomerular epithelial cells which face the GBM, especially in the proximity of immune deposits (Fig. 2, $A, B$, and $E)$. Labeling of cytoplasmic vesicles was also observed to a lesser extent in mesangial and endothelial cells. Control preparations in which the first antibodies were excluded showed no labeling (not shown).

Localization of adducts in isolated GBMs. Detergent extraction of unfixed cryostat sections resulted in complete dissolution of the cellular material, leaving basement membranes attached to the slides. The GBMs of proteinuric rats with 7-d PHN showed a fine granular, almost linear, fluorescent signal when immunolabeled for MDA adducts (Fig. 3, right), but basement membranes from normal controls were almost negative (Fig. 3 , left), indicating that LPO products are present not only in 


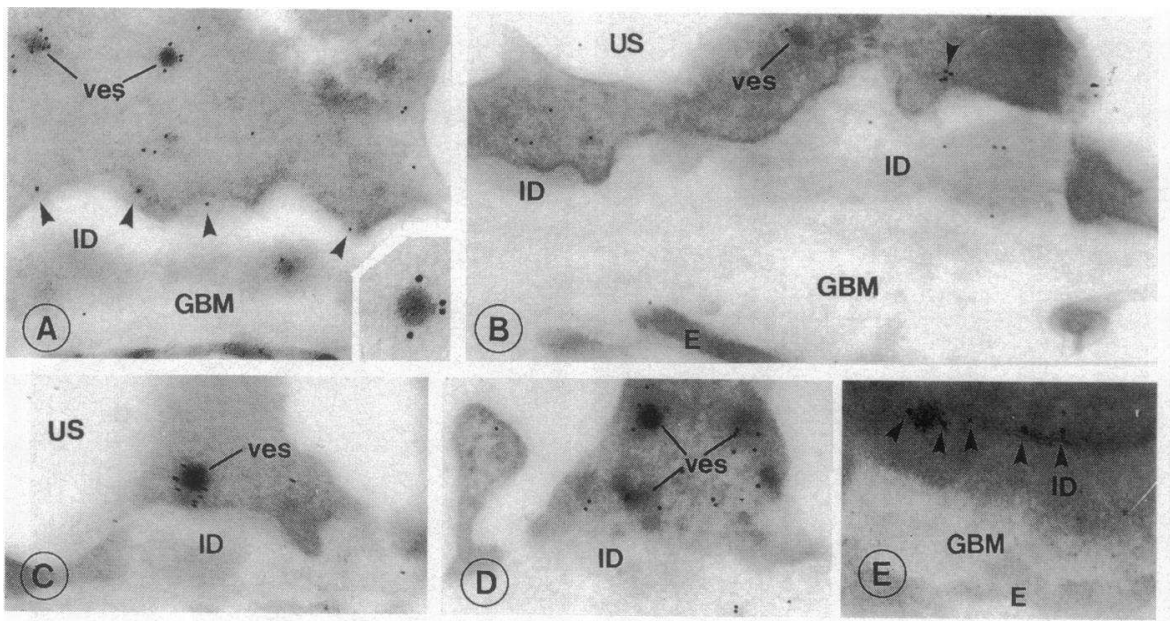

Figure 2. Localization of MDA adducts within glomeruli from proteinuric rats with 7-d PHN by indirect immunogold labeling using monoclonal MDA-specific antibody on ultrathin frozen sections of formaldehydefixed renal tissue. Gold particles are shown primarily in association with glomerular epithelial cells, within their cytoplasm ( $A$ and $D)$, in cytoplasmic vesicles $(A, C$, and $D)$, and on the cell membrane facing the GBM, sometimes adjacent to immune deposits (ID), and within the GBM $(A, B$, and $E)$. Occasionally gold particles are encountered within immune deposits $(B) . A-D$, $\times 25,000 ; E, \times 48,000$. glomerular cells but also in the matrix of the GBM from PHN rats.

Identification of MDA-modified glomerular proteins. Glomeruli from normal controls and 7-d PHN-rats were isolated and dissolved in SDS-sample buffer, and $50 \mu \mathrm{g}$ of protein from each preparation was subjected to SDS-gel electrophoresis and immunoblotting. When immunoblotted with MDA-2 antibody, several bands from the 7-d PHN glomeruli were labeled, the most prominent at $\sim 220 \mathrm{kD}$ and variably, at much lower intensity, at $\sim 240 \mathrm{kD}$, as well as 180,95 , and $65 \mathrm{kD}$ (Fig. 4). The guinea pig anti-MDA and anti-4-HNE IgG antibodies bound to bands of similar molecular size (not shown). Immunostaining of normal glomerular proteins, which were processed in parallel under exactly the same conditions, revealed only trace staining of the $\sim 220-\mathrm{kD}$ band with MDA-2 antibody (Fig. 4).

Identification of type $I V$ collagen as a recipient of $M D A$ adduct formation. The above data suggested that GBM proteins from rats with 7-d PHN were modified by MDA. Since type
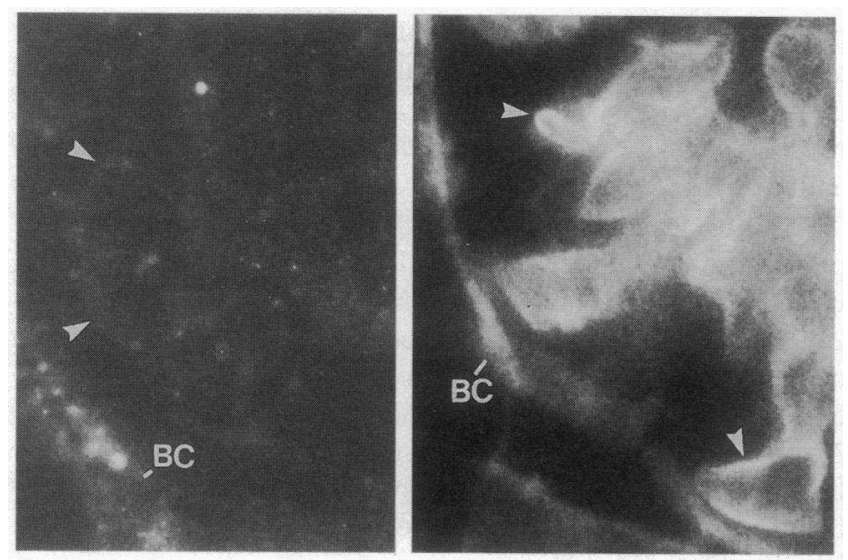

Figure 3. Detection of LPO adducts on isolated rat GBMs from normal and proteinuric, 7-d PHN rats. Basement membrane preparations were produced by removal of cellular material from cryostat sections of rat kidneys with detergents, followed by indirect immunofluorescence with monoclonal anti-MDA antibody. Left, normal rat GBMs are only weakly stained. Right, cell-free GBM preparations obtained from 7-d PHN rats are immunolabeled in a fine granular, diffuse pattern (arrowheads) indicating that GBM matrix proteins are modified by LPO adducts. $B C$, Bowman's capsule basement membrane. $\times 1,000$.
IV collagen is a major component of the GBM, we performed an immunochemical analysis of proteins extracted from 7-d PHN rat glomeruli separated on 5-15\% gradient SDS gels and immunoblotted with anti-MDA and anti-rat type IV collagen antibodies. With both antibodies $\mathrm{a} \sim 220-\mathrm{kD}$ band was prominently labeled, suggesting that a component of type IV collagen was modified by LPO products (Fig. 5). Antibodies to laminin and fibronectin labeled predominately bands of an apparent molecular mass of $\sim 230$ and $\sim 240 \mathrm{kD}$ (data not shown), respectively, which were not matched by MDA-modified glomerular proteins.

As another strategy to confirm MDA adduct formation with type IV collagen, isolated GBMs of normal and of proteinuric 7-d PHN rats were labeled with ${ }^{3} \mathrm{H}$-cyanoborohydride to specifically incorporate ${ }^{3} \mathrm{H}$ into MDA-Schiff bases with available amino groups, such as $\epsilon$-amino groups of lysine residues (25). When $50 \mu \mathrm{g}$ of protein from GBM lysates was loaded onto SDS gels and autoradiographed, a prominent $\sim 220-\mathrm{kD}$ and 


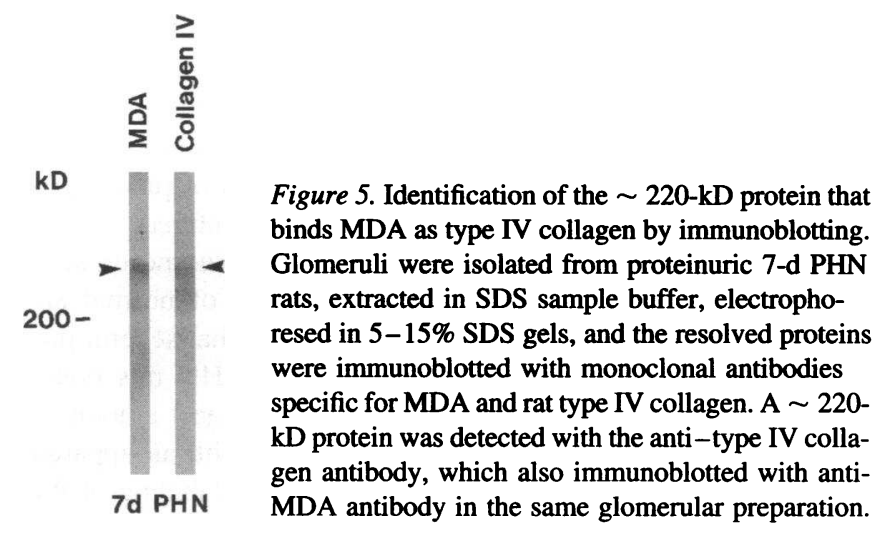

a weaker $\sim 440-\mathrm{kD}$ band were shown to have incorporated radioactivity in normal GBMs (Fig. 6, lane $C$ ). Incorporation of ${ }^{3} \mathrm{H}$-label into these bands was greatly enhanced in GBMs from 7-d PHN rats with proteinuria (Fig. 6, lane $D$ ).

When solubilized radiolabeled GBMs of 7-d PHN rats were immunoprecipitated with antibodies to type IV collagen, the $\sim 220-\mathrm{kD}$ and the $\sim 440-\mathrm{kD}$ bands were specifically bound (Fig. 6, lane $E$ ). By contrast, antibodies to laminin, heparan

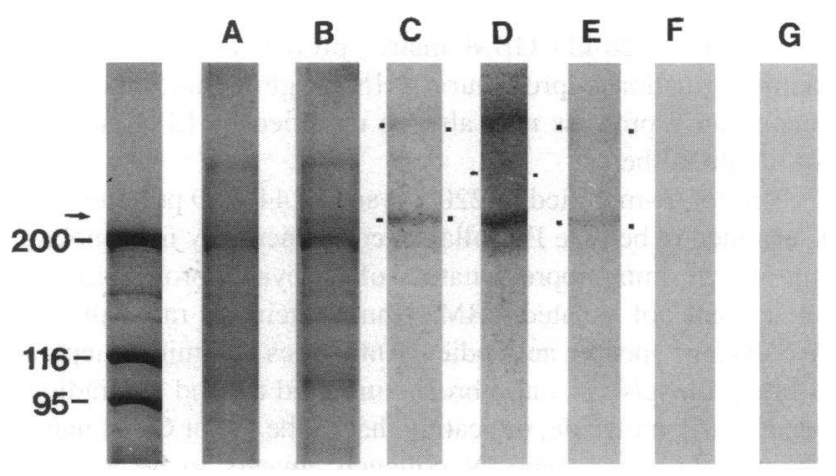

Figure 6. Identification of type IV collagen as a major protein modification by MDA adducts in 7-d PHN rat GBM. Glomeruli from normal and 7-d PHN rats were extracted with deoxycholate, labeled in their Schiff bases using ${ }^{3} \mathrm{H}$-cyanoborohydride, followed by immunoprecipitation with antibodies specific for extracellular matrix proteins. $A$ and $B$, Coomassie blue-stained gels of extracts from normal $(A)$ and proteinuric 7-d PHN $(B)$ rat GBMs, showing that the same amount of protein was loaded in each preparation; $C$ and $D$, autoradiographs of lanes $A$ and $B$, showing ${ }^{3} \mathrm{H}$-labeled bands in the GBMs of normal controls $(C)$ and 7-d PHN rats $(D)$. The major bands labeled correspond to a $\sim 220$ $\mathrm{kD}$ and $\mathrm{a} \sim 440-\mathrm{kD}$ protein, as well as $\mathrm{a} \sim 250-\mathrm{kD}$ protein (marked by $d o t s$ ). In proteinuric rats the same pattern of proteins is labeled, but more specific activity is detected, indicating that more Schiff bases are present in proteinuric GBMs than in controls. $E$, autoradiograph of the immunoprecipitate of detergent lysates of ${ }^{3} \mathrm{H}$-labeled GBMs from 7-d PHN rats, obtained with anti-type IV collagen antibody which specifically immunoprecipitates proteins with apparent molecular masses of $\sim 220$ and $\sim 440 \mathrm{kD} . F$ and $G$, immunoprecipitates with antibodies specific for laminin and heparan sulfate proteoglycan-core protein which fail to bind to any ${ }^{3} \mathrm{H}$-labeled GBM protein. This indicates that type IV collagen contains most Schiff bases in GBMs of proteinuric rats with PHN and that this molecule is also dimerized by the bifunctional aldehydes generated as a consequence of LPO. The left lane shows globular protein molecular mass standards, and the arrow indicates the position of the type I collagen $\beta$-chain which was used as a fibrillar protein standard.

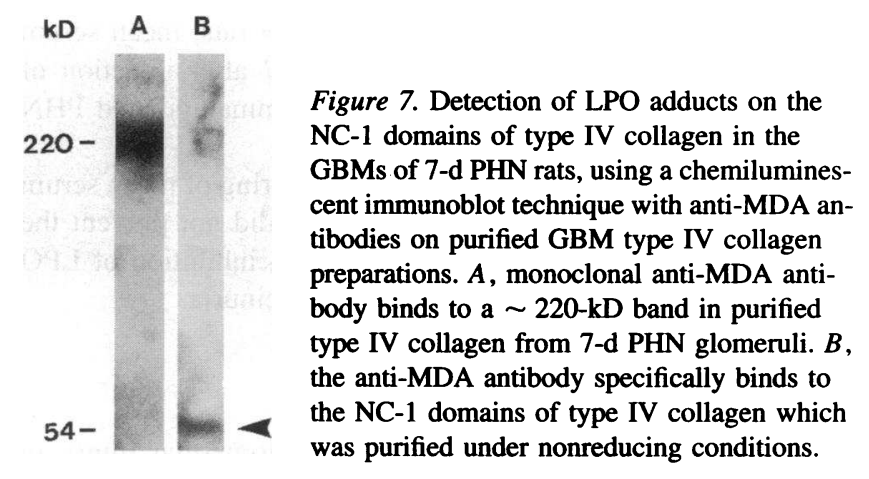

sulfate proteoglycan, and fibronectin failed to bind any radiolabeled GBM proteins (Fig. 6, lanes $F$ and $G$ ). These data demonstrate that modification of type IV collagen by MDA is greatly enhanced in the 7-d PHN rat glomerulus.

MDA adduct formation on the NC-1 domain. The NC-1 domain was liberated from GBM type IV collagen by collagenase treatment, and was identified as a 54-kD fragment (under nonreducing conditions) by immunoblotting, using an NC-1 domain-specific antibody. When isolated from 7-d PHN rat glomeruli and enriched by immunoprecipitation with anti-NC-1 antibody, MDA-2 antibody specifically bound to this same 54$\mathrm{kD}$ fragment (Fig. 7, lane $B$ ), thereby indicating the presence of MDA adducts on the NC-1 domain.

Probucol inhibition of proteinuria. As listed in Table $\mathrm{I}$, the mean 24-h proteinuria in $6 \mathrm{PHN}$ rats was $161.0 \pm 24 \mathrm{mg}$, compared with that of 11 probucol pretreated PHN rats which was significantly less $(24.8 \pm 8.0 \mathrm{mg}, P<0.01)$. Rats pretreated with simvastatin $(n=11)$ to achieve similar serum cholesterol levels at induction of PHN as those measured in rats given probucol did not show a significant reduction in 24-h proteinuria (216 $\pm 18.5 \mathrm{mg}, P>0.05)$.

Mean serum cholesterol level of 10 normal control rats was $2.28 \pm 0.04 \mathrm{mM} /$ liter. Probucol-and simvastatin-treated rats at initiation of PHN were $1.97 \pm 0.01$ and $1.95 \pm 0.01 \mathrm{mM} /$ liter, respectively $(P>0.05)$, values significantly lower than those of normal rats $(P<0.05)$ and those of $7-\mathrm{d}$ PHN rats without pretreatment $(4.27 \pm 0.02 \mathrm{mM} /$ liter, $P<0.01)$. However, in

Table 1. Proteinuria in Passive Heymann Nephritis: Response to Pretreatment with Probucol or Simvastatin

\begin{tabular}{cccc}
\hline & \multicolumn{2}{c}{ Serum cholesterol } & \\
\cline { 2 - 3 } Group* & Start PHN & $7 \mathrm{~d}$ & $\begin{array}{c}\text { Proteinuria at } \\
7 \mathrm{~d}\end{array}$ \\
\hline & $m M$ Miter & $m M$ Miter & $m g / 24 \mathrm{~h}$ \\
$\begin{array}{c}\text { Normal controls } \\
(n=10) \\
\mathrm{PHN} \\
(n=6)\end{array}$ & $2.28 \pm 0.04$ & $2.2 \pm 20.06$ & $6.8 \pm 0.4$ \\
$\begin{array}{c}\text { Probucol }+ \text { PHN } \\
(n=11)\end{array}$ & $2.26 \pm 0.08$ & $4.27 \pm 0.02$ & $161.2 \pm 24$ \\
$\begin{array}{c}\text { Simvastatin }+ \text { PHN } \\
(n=11)\end{array}$ & $1.97 \pm 0.01$ & $1.95 \pm 0.04$ & $24.8 \pm 8.0$ \\
\hline
\end{tabular}

* Treated rats were given probucol or simvastatin for $21 \mathrm{~d}$ before induction of PHN. Values are mean \pm standard deviation. 
both probucol- and simvastatin-treated PHN rats, mean serum cholesterol values were decreased at day 7 after injection of anti-Fx1A antibody when compared with unmanipulated PHN rats $(P<0.05)$.

These experiments indicate that the lowering of mean serum cholesterol levels per se in rats with PHN did not prevent the development of the proteinuria. In contrast, inhibition of LPO by probucol markedly ameliorated the proteinuria.

\section{Discussion}

Proteinuria is the major consequence of glomerular injury in membranous nephropathy, as well as in other forms of immunologic renal diseases. In PHN, an experimental form of membranous nephropathy in rats, the development of proteinuria depends mainly on the local formation of the C5b-9 membrane attack complex of complement (for review see reference 28) and production of ROS by glomerular cells $(7,8)$. In this study we provide evidence for the ROS-mediated formation of LPO adducts on type IV collagen of the GBM and for their relevance in the pathogenesis of proteinuria.

ROS are produced in PHN in situ by intrinsic glomerular cells, especially by the epithelial cells, and then diffuse into the GBM (8). This raised the question of whether or not LPO occurred in this setting and if and where LPO-mediated adduct formation was localized. To address these questions we have used antibodies specific for characteristic LPO-induced adducts, MDA-lysine or 4-HNE-lysine, that result from the formation of Schiff bases of highly reactive aldehydic fragments of oxidized polyunsaturated fatty acids and of $\epsilon$-amino groups of the lysine residues within proteins (29). These antibodies were originally generated to document the presence of oxidized LDL $(20,21)$ and do not show reactivity with native, unoxidized LDL or other unmodified proteins (20). Furthermore, competition studies have indicated that these antibodies recognize the adducts when present on a variety of different proteins $(20-22)$. With these reagents we localized MDA and 4-HNE adducts in highest concentration within glomeruli of proteinuric rats with PHN, whereas reactivity with normal rat glomeruli was minimal, indicating that LPO occurs within PHN glomeruli, in temporal correlation with proteinuria.

The precise localization of the MDA adducts in glomeruli of proteinuric PHN rats was investigated by immunogold electron microscopy. MDA-modified proteins were found in highest concentration in glomerular epithelial cells, particularly in association with membranes of cytoplasmic vesicles, as well as along the glomerular epithelial cell membrane that faces the GBM, and in proximity to immune deposits, in agreement with the granular distribution of MDA adducts observed by immunofluorescence microscopy. A simple, and the most likely, explanation for these observations is that the LPO-mediated adducts are produced locally within the capillary walls. It is also conceivable, but not likely, that the immunohistochemical signal is derived from MDA-modified proteins which were taken up by the glomerular epithelial cells from the circulation.

Immunogold electron microscopy applied to intact renal tissue is not able to completely distinguish adducts associated with the GBM from those on epithelial cell membranes. We therefore isolated basement membranes by removal of the cellular material with detergents from cryostat sections of rat kidneys. When incubated with anti-MDA antibodies, specific immunolabeling was found in the GBMs of proteinuric rats, but not in normal controls, thus providing evidence for the accumulation of LPO adducts within the matrix of the GBM in proteinuric rats.

These findings raised the intriguing possibility that LPO adduct formation could directly affect matrix proteins of the GBM and could impact on the molecular basis of proteinuria. To determine which matrix protein(s) was modified by LPO adduct formation, we have compared the pattern and quantity of MDA-modified glomerular matrix proteins of normal and proteinuric rats by immunoblotting. We noted that several proteins from lysates obtained from proteinuric PHN rats bound anti-MDA and anti-4-HNE antibodies. The largest amount of MDA adducts was associated with a protein with an apparent molecular mass of $\sim 220 \mathrm{kD}$. The intensity of labeling of this protein was greatly increased in lysates of proteinuric glomeruli, when compared with normal controls, thus suggesting that this molecule is modified by MDA adducts. Further evidence of the importance of the $\sim 220-\mathrm{kD}$ protein as a site of MDA modification was obtained independently by experiments using isolated GBMs of normal and proteinuric rats with 7-d PHN, in which Schiff base formation was demonstrated by incorporation of ${ }^{3} \mathrm{H}$-cyanoborohydride (26). When solubilized radiolabeled GBM matrix proteins from proteinuric PHN rats were loaded onto SDS gels and autoradiographed, Schiff base formation was confined again to a prominent $\sim 220-\mathrm{kD}$ protein, and to a lesser extent to a $\sim 440-\mathrm{kD}$ protein, whereas relatively small amounts of ${ }^{3} \mathrm{H}$ were incorporated into normal GBMs. Clearly, a $\sim 220-\mathrm{kD}$ GBM matrix protein is a site of LPO adduct formation in proteinuric $\mathrm{PHN}$ 'rat glomeruli; other additional matrix proteins may also be modified by LPO but were not identified here.

The MDA-modified $\sim 220-\mathrm{kD}$ and $\sim 440-\mathrm{kD}$ proteins were determined to be type IV collagen components by immunoblotting and by immunoprecipitation of ${ }^{3} \mathrm{H}$-cyanoborohydride-labeled lysates of isolated GBMs from proteinuric rats with type IV collagen-specific antibodies. Antibodies to laminin, heparan sulfate proteoglycan, and fibronectin failed to bind any radiolabeled matrix molecule, indicating that of the major GBM matrix components tested, type IV collagen appears to be most intensely modified by MDA-Schiff bases. It is plausible that the $\sim 220-\mathrm{kD}$ band observed corresponds to an $\alpha 1$-chain monomer of type IV collagen, and the $\sim 440-\mathrm{kD}$ band to a dimer. This is consistent with the finding that MDA is a highly reactive dialdehyde which is known to dimerize proteins, for example serum albumin in iron-overloaded rats (30).

Amino acid sequencing of type IV collagen has revealed that the noncollagenous, globular NC-1 domain is particularly rich in dibasic amino acids which are responsible for the high isoelectric point of this fragment (31). Since Schiff base formation with MDA and 4-HNE requires the $\epsilon$-amino groups of these amino acids, it was of interest to examine the possibitity that the NC-1 domain was a major site of adduct formation. We have provided evidence that this was indeed the case, because purified NC-1 domains of GBMs of proteinuric PHN rats strongly reacted with the anti-MDA antibody. This implies that the MDA has crosslinked two different collagen molecules, presumably via their NC-1 domains, consistent with a $\sim 440$ $\mathrm{kD}$ dimer of collagen monomers noted above.

Collectively, the above findings raised the question as to whether or not LPO-induced adduct formation was relevant to the development of proteinuria in PHN. The contribution of LPO to glomerular damage was examined by pretreating rats before injection of nephritogenic anti-Fx1 A antibodies with pro- 
bucol, a highly lipophilic antioxidant that efficiently inhibits LPO (17-19). Probucol is known to partition into cell membranes in vitro and in vivo, and to bind to circulating low density lipoprotein (32). In this study we have shown that pretreatment of rats with probucol inhibited proteinuria by $>80 \%$ and profoundly reduced the amount of MDA adducts in glomeruli, as observed by indirect immunofluorescence microscopy with specific antibody. This occurred even though the formation of immune deposits was not affected in the probucol-treated rats and indicates that probucol inhibited events occurring after local immune complex formation. These observations, in conjunction with our biochemical and immunomorphological data, strongly support a role for LPO in the development of proteinuria in PHN.

Since probucol significantly lowered the mean serum cholesterol levels in normal and PHN rats, we examined the relevance of the hypercholesterolemia that accompanied PHN to the development of proteinuria, although the elevation of serum cholesterol has not been shown to induce acute renal injury or proteinuria. However, evidence is accumulating that chronic hyperlipidemia may contribute to the development of chronic glomerular injury (33-35). By contrast, hypercholesterolemia follows the development of proteinuria in PHN. When rats were pretreated with simvastatin and mean serum cholesterol levels were reduced to a value similar to that obtained by probucol pretreatment, no ameliorating effect on the development of proteinuria in PHN was observed. Simvastatin-pretreated PHN rats were not hypercholesterolemic at $7 \mathrm{~d}$ when proteinuric, unlike unmanipulated PHN rats. These observations suggest that, after in situ glomerular immune complex formation, locally produced ROS exert their damaging effect on the glomerular capillary wall to a large extent by means of locally initiated LPO and that probucol pretreatment inhibits this process with a consequent reduction in proteinuria. Hyperchelesterolemia is not required for this process to occur, though it may be exaggerated if present. It should, however, be emphasized that formation of adducts could be only one of several reactions which are consequences of local lipid peroxidation with GBM components.

It is intriguing that the LPO adduct formation in the GBM matrix could be a further example of the involvement of type IV collagen, and in particular of its NC-1 domain, in the pathogenesis of renal disease. Other examples are in situ GBM immune complex formation in Goodpasture's syndrome, the nephritogenic antigen residing in the $\alpha 3$ chain within the NC1 domain of type IV collagen (36), and amino acid sequence aberrations in the NC-1 domain in Alport's syndrome (37). It appears therefore that LPO-mediated or direct immune injury to components of the $\mathrm{NC}-1$ domain or alterations in its structure are associated with various types of glomerular damage and could provide a common target of glomerular capillary wall injury in various otherwise unrelated diseases. Thus, it will be of considerable interest to examine the relevance of LPOmediated glomerular damage in other experimental systems and in human renal diseases in particular.

\section{Acknowledgments}

This work was supported by the Fonds zur Förderung der Wissenschaftlichen Forschung Project P 10433 Med (to D. Kerjaschki), by Clintec Technologies (Deerfield, IL) and the Research Trust Funds of the Wellington Area Health Board ( to T. J. Neale), and by a grant from National Heart, Lung and Blood Institute (SCOR HL-14197, to J. L. Witztum).

\section{References}

1. Schwartz, M. M. 1992. Membranous glomerulonephritis. In Pathology of the Kidney. R. H. Heptinstall, editor, Little, Brown and Company, Boston/Toronto/London. 559-626.

2. Couser, W. G., and D. J. Salant. 1980. In situ immune complex formation and glomerular injury. Kidney Int. 17:1-13.

3. Kerjaschki, D. 1993. Molecular pathogenesis of membranous nephropathy. Kidney Int. 41:1090-1105.

4. Kerjaschki, D., and M. G. Farquhar. 1982. The pathogenic antigen of Heymann nephritis is a membrane glycoprotein of the renal proximal tubular brush border. Proc. Natl. Acad. Sci. USA. 79:5557-5561.

5. Kerjaschki, D., R. Ullrich, K. Diem, S. Pietromonaco, R. Orlando, and M. G. Farquhar. 1992. Identification of a pathogenic epitope involved in initiation of Heymann nephritis. Proc. Natl. Acad. Sci. USA. 89:11179-11183.

6. Verroust, P. 1989. Kinetics of immune deposits in membranous nephropathy. Kidney Int. 38:1418-1428.

7. Shah, S. V. 1988. Evidence suggesting a role for hydroxyl radical in passive Heymann's nephritis. Am. J. Physiol. 254:F337-F344.

8. Neale, T. J., R. Ullrich, P. P. Ohja, H. Poczewski, A. J. Verhoeven, and D. Kerjaschki. 1993. Reactive oxygen species and neutrophil respiratory burst cytochrome $b_{558}$ are produced by kidney glomerular cells in passive Heymann nephritis. Proc. Natl. Acad. Sci. USA. 90:3645-3649.

9. Verhoeven, A. J., B. G. J. M. Bolscher, L. J. Meerhof, R. van Zwjeten, J. Keijer, R. S. Weening, and R. Roos. 1989. Characterisation of two monoclonal antibodies against cytochrome $b_{5 s 8}$ of human neutrophils. Blood. 73:1686-1694.

10. Fong, L. G., S. Parthasarathy, J. L. Witztum, and D. Steinberg. 1987. Nonenzymatic oxidative cleavage of peptide bonds in apoprotein $\mathrm{B}_{100}$. J. Lipid Res. 28:1466-1477.

11. Johnson, R. J., S. J. Klebanoff, R. Ochi, S. Adler, P. Baker, L. Sparus, and W. G. Couser. 1987. Participation of the myeloperoxidase- $\mathrm{H}_{2} \mathrm{O}_{2}$-halide system in immune complex nephritis. Kidney Int. 32:342-349.

12. Witztum, J. L. 1993. Role of oxidised low density lipoprotein in atherogenesis. Br. Heart J. 69:S12-S18.

13. Chisholm, G. M., K. C. Irwin, and M. S. Penn. 1992. Lipoprotein oxidation and lipoprotein-induced cell injury in diabetes. Diabetes. 41:61-66.

14. Modi, K. S., J. Morrissey, S. V. Shah, G. F. Schreiner, and S. Klahr. 1990. Effects of probucol on renal function in rats with bilateral ureteral obstruction. Kidney Int. 38:843-850.

15. Kawamura, T., T. Yoshioka, T. Bills, A. Fogo, and I. Ichikawa. 1991. Glucocorticoid activates glomerular anti-oxidant enzymes and protects glomeruli from oxidant injury. Kidney Int. 40:291-301.

16. Bradford, M. M. 1976. A rapid and sensitive method for the quantitation of microgram quantities of protein utilizing the principle of protein-dye binding. Anal. Biochem. 72:248-254.

17. Parthasarathy, S., S. G. Young, J. L. Witztum, R. C. Pittman, and D. Steinberg. 1986. Probucol inhibits oxidative modification of low density lipoprotein. J. Clin. Invest. 77:641-644.

18. Carew, T. E., D. C. Schwenke, and D. Steinberg. 1987. Anti-atherogenic effect of probucol unrelated to its hypocholesterolemic effect: evidence that antioxidants in vivo can selectively inhibit low density lipoprotein degradation in macrophage-rich fatty streaks slowing the progression of atherosclerosis in the WHHL rabbit. Proc. Natl. Acad. Sci. USA. 84:7725-7729.

19. Steinberg, D. 1991. Antioxidants and atherosclerosis: a current assessment. Circulation. 84:1420-1425.

20. Palinski, W., S. Yla-Herttuala, M. E. Rosenfeld, S. W. Butler, S. A. Socher, S. Parthasarathy, L. K. Curtiss, and J. L. Witztum. 1990. Antisera and monoclonal antibodies specific for epitopes generated during oxidative modification of low density lipoprotein. Arteriosclerosis. 10:325-335.

21. Palinski, W., M. E. Rosenfeld, S. Yla-Herttuala, G. C. Gurtner, S. S. Socher, S. W. Butler, S. Parthasarathy, T. E. Carew, D. Steinberg, and J. L. Witztum. 1989. Low density lipoprotein undergoes oxidative modification in vivo. Proc. Natl. Acad. Sci. USA. 86:1372-1376.

22. Steinbrecher, U. P., M. Fisher, J. L. Witztum, and L. K. Curtiss. 1984. Immunogenicity of homologous low density lipoprotein after methylation, ethylation, acetylation, or carbamylation: generation of antibodies specific for derivatized lysine. J. Lipid Res. 25:1109-1116.

23. Kerjaschki, D., H. Sawada, and M. G. Farquhar. 1986. Immunoelectron microscopy in kidney research: some contributions and limitations. Kidney Int. 30:229-245

24. Tokoyasu, K. T. 1989. Immunohistochemistry on ultrathin frozen sections. Histochem. J. 21:163-171.

25. Kerjaschki, D., H. Poczewski, G. Dekan, R. Horvat, E. Balzar, N. Kraft, and R. C. Atkins. 1986. Identification of a major sialoprotein in the glycocalyx of human visceral glomerular epithelial cells. J. Clin. Invest. 78:1142-1149.

26. Witztum, J. L., U. P. Steinbrecher, M. Fisher, and A. Kesaniemi. 1983. Nonenzymatic glucosylation of autologous LDL and albumin render them immunogenic in the guinea pig. Proc. Natl. Acad. Sci. USA. 80:2757-2769.

27. Richmond, W. 1973. Preparation and properties of a cholesterol oxidase 
from Nocardia species and its application to the enzymatic assay of total cholesterol in serum. Clin. Chem. 19:1350-1356.

28. Couser, W. G. 1990. Mediation of immune glomerular injury. J. Am. Soc. Nephrol. 1:13-29.

29. Esterbauer, H., G. Jurgens, O. Quehenberger, and E. Koller. 1987. Autooxidation of human low density lipoprotein: loss of polyunsaturated fatty acids and vitamin E and generation of aldehydes. J. Lipid Res. 28:495-509.

30. Houglum, K., M. Filip, J. L. Witztum, and M. Chojkier. 1990. Malondialdehyde and 4-hydroxynonenal protein adducts in plasma and liver of rats with iron overload. J. Clin. Invest. 86:1991-1998.

31. Turner, N., P. J. Mason, R. Brown, M. Fox, S. Povey, A. Rees, and C. D. Pusey. 1992. Molecular cloning of the human Goodpasture antigen demonstrates it to be the $\alpha 3$ chain of type IV collagen. J. Clin. Invest. 89:592-601.

32. Urien, S., P. Riant, E. Albengres, R. Briovde, and J. P. Tillement. 1984.
In vitro studies on the distribution of probucol among human lipoproteins. Mol. Pharmacol. 26:322-327.

33. Kaysen, G. A. 1991. Hyperlipidemia of the nephrotic syndrome. Kidney Int. 39:S8-S15.

34. Diamond, J. R. 1991. Analogous pathobiologic mechanisms in glomerulosclerosis and atherosclerosis. Kidney Int. 31:S29-S34.

35. Grond, J., J. J. Weening, and J. B. Elema. 1984. Glomerular sclerosis in nephrotic rats. Lab. Invest. 51:277-285.

36. Butowski, R. J., J. P. M. Langeveld, J. Wieslander, J. Hamilton, and B. G. Hudson. 1987. Localization of the Goodpasture epitope to novel chain of basement membrane collagen. J. Biol. Chem. 262:7874-7877.

37. Reeders, S. T. 1992. Molecular genetics of hereditary nephritis. Kidney Int. 42:783-792. 